\title{
Harmless treatment method of dead chickens in scale chicken farm
}

\author{
Chunlin $\mathrm{Yu}^{1}$, Bo Xia ${ }^{1}$, Mohan $\mathrm{Qiu}^{2}$, Longhuan $\mathrm{Du}^{3}$, Zengrong Zhang ${ }^{1,2}$, Xiaoyan Song ${ }^{1,2}, \mathrm{Xia}^{\mathrm{X}}$ iong ${ }^{2}, \mathrm{Chenming} \mathrm{Hu}^{1,2}$,
} Li Yang ${ }^{2}$, Chaowu Yang ${ }^{1, *}$

${ }^{1}$ Sichuan Animal Science Academy, 610066, Chengdu, Sichuan, China

${ }^{2}$ Animal Breeding and Genetics Key Laboratory of Sichuan Province, 610066, Chengdu, Sichuan, China

${ }^{3}$ Sichuan University, 610000, Chengdu, Sichuan, China

\begin{abstract}
The harmless treatment of dead chickens is an important content in poultry production. This paper compared the effects of the harmless treatment of dead chickens by adding different disinfectants, including quicklime and calcium hypochlorite. The results showed that both quicklime and calcium hypochlorite could increase the total bacteria content, improve the harmless treatment capacity, and shorten the killing time of Escherichia coli and Staphylococcus aureus. The effect of quicklime was better than that of calcium hypochlorite. The experiment provided practical guidance for harmless treatment of scale chicken farm.
\end{abstract}

\section{Introduction}

Large-scale is one of the characteristics and the development direction of poultry production. The intensive and high-density raising mode has greatly increased the probability of animal epidemic infection and death, and the public health safety problems caused by animal diseases have become increasingly prominent. The annual mortality rate of poultry caused by various diseases in China is reported about $12 \%$ to $20 \%^{[1]}$. However, less than $20 \%$ of livestock and poultry are buried after dying from diseases, and even fewer can be treated with harmless chemicals ${ }^{[2]}$. Since the 1980 s, epidemic diseases such as highly pathogenic avian influenza (HPAI) and Newcastle disease (ND) epidemics have occurred occasionally. European and American developed countries had attached great importance to the harmless treatment of animal carcass, continued to strengthen the system construction, and formed a series of disposal operations manual and specifications disposal method, which largely prevented the spread of animal epidemics, effectively controlled and exterminated animal epidemic ${ }^{[3]}$.

The methods of harmless treatment of chickens' carcass include deep burial, incineration, fermentation, Chemical processing method, biodegradation and other methods, which has different applications as well as advantages and disadvantages. For example, in United States and Australia, corpses of livestock and poultry with small body size are mostly dealt in fixed cinerators, which can completely kill pathogenic microorganisms and minimize the volume of dead individuals. Nevertheless, incineration process will produce a lot of harmful gases and cause air pollution, and the cost is $\operatorname{high}^{[4]}$.

Deep burial method refers to the way of putting dead chickens into deep buried pits and covering and disinfecting them according to relevant regulations. Generally, a thickness of $2 \mathrm{~cm}$ to $5 \mathrm{~cm}$ quicklime or calcium hypochlorite is sprinkled at the bottom of the pit. It is a common method of harmless treatment, which has the advantages of simple operation, economic applicability and is suitable for farms of all scales. In this paper, the innocuous treatment ability and the killing ability of pathogenic bacteria were studied by adding different disinfectant deep buried methods.

\section{Materials and methods}

\subsection{Treatment}

Three deep buried pits with volume of $1 \times 1 \times 1 \mathrm{~m}^{3}, 24$ wall structure and anti-seepage treatment are numbered A, B and $C$ respectively. After 5 dead chickens with similar body weight were put into each group, groups A and B were covered with quicklime and calcium hypochlorite, respectively. Group $\mathrm{C}$ was the control group without any disinfectant. The test period was from October 2018 to September 2019 out door.

\subsection{Sample}

Samples were taken every 3 months during the test, and 5 tubes of $8 \mathrm{ml}$ effusion was collected from each deep pit and stored in sterile centrifuge tubes for reserve.

\footnotetext{
* Corresponding author: cwyang@foxmail.com
} 


\subsection{Laboratory measurement}

The total bacteria content was determined by dilution plate counting method. Effusion was diluted with PBS buffer to 7 gradients, $10^{-1}$ to $10^{-7}$. The contents of E. coli and S. aureus were determined by MACC medium and MSA medium. Each test set up 3 replicates.

\subsection{Statistical analysis}

The total bacteria content results were analyzed by SAS (SAS Institute, Inc. 2000) and illustrated in the form of 'mean \pm standard deviation'. Means were compared and significance was declared based on least significant difference at probability by $\mathrm{T}$-test, $\mathrm{P} \leq 0.05$.

\section{Results}

\subsection{Decomposition ability of chicken carcass}

Total bacteria count results in each group were shown in Table 1. In the first three tests, the total bacteria number of the effusion in group A (quicklime), group B (calcium hypochlorite) and group $\mathrm{C}$ (control group) showed a trend of significant increase as time gone by, and significantly decreased in the fourth test compared with the third. The total number of bacteria in group A (quicklime) was significantly higher than that in group B (calcium hypochlorite) and group C (control group), and there was significant difference between group B (calcium hypochlorite) and group C (control group) at each detection time point.

Table 1 Total bacteria count in each group (CFU/g)

\begin{tabular}{|c|c|c|c|}
\hline Test Time (2019) & GroupA & GroupB & Group C \\
\hline Jan. & $\begin{array}{c}2.27 \pm 0.43 \\
\left(\times 10^{7}\right)^{\mathrm{Aa}}\end{array}$ & $\begin{array}{c}1.37 \pm 0.14 \\
\left(\times 10^{7}\right)^{\mathrm{Ba}}\end{array}$ & $\begin{array}{c}1.87 \pm 0.19 \\
\left(\times 10^{6}\right)^{\mathrm{Ca}}\end{array}$ \\
\hline Feb. & $\begin{array}{c}2.42 \pm 0.24 \\
\left(\times 10^{8}\right)^{\mathrm{Ab}}\end{array}$ & $\begin{array}{c}1.90 \pm 0.17 \\
\left(\times 10^{8}\right)^{\mathrm{Bb}}\end{array}$ & $\begin{array}{c}4.70 \pm 0.48 \\
\left(\times 10^{7}\right)^{\mathrm{Cb}}\end{array}$ \\
\hline Jul. & $\begin{array}{l}1.78 \pm 0.19 \\
\left(\times 10^{10}\right)^{\mathrm{Ac}}\end{array}$ & $\begin{array}{c}2.99 \pm 0.33 \\
\left(\times 10^{9}\right)^{\mathrm{Bc}}\end{array}$ & $\begin{array}{c}1.48 \pm 0.16 \\
\left(\times 10^{8}\right)^{\mathrm{Cc}}\end{array}$ \\
\hline Sep. & $\begin{array}{c}9.00 \pm 0.95 \\
\left(\times 10^{8}\right)^{\mathrm{Ad}}\end{array}$ & $\begin{array}{c}4.80 \pm 0.49 \\
\left(\times 10^{7}\right)^{\mathrm{Bd}}\end{array}$ & $\begin{array}{c}3.70 \pm 0.45 \\
\left(\times 10^{6}\right)^{\mathrm{Cd}}\end{array}$ \\
\hline
\end{tabular}

Group A, quicklime; Group B, calcium hypochlorite; Group C, control group.

Different upper letters in the same rows indicated significant difference $(\mathrm{P}<0.05)$.

Different lowercase in the same columns indicated significant difference $(\mathrm{P}<0.05)$.

\subsection{Killing ability of harmful bacteria}

The number of E.coli and S. aureus were determinated by MACC medium and MSA selection medium and the results (Table 2) demonstrated that group A, B, C can effectively kill harmful bacteria. However, the kill rate was different, where group A(quicklime) was the fastest, group B (calcium hypochlorite) was the second and group C (control group) was the slowest.

Table 2. Killing situation of E. coli and S. aureus

\begin{tabular}{|c|c|c|c|c|c|c|}
\hline \multirow{2}{*}{$\begin{array}{c}\text { Test Time } \\
(2019)\end{array}$} & \multicolumn{2}{|l|}{ quicklime } & \multicolumn{2}{l|}{ calcium hypochlorite } & \multicolumn{2}{l|}{ control } \\
\cline { 2 - 7 } & A & B & A & B & A & B \\
\hline Jan. & + & + & + & + & + & + \\
\hline Feb. & - & + & + & - & + & + \\
\hline Jul. & - & - & - & - & - & - \\
\hline Sep. & - & - & - & & \\
\hline $\begin{array}{l}\text { A, E.coli; B,S. aureus. } \\
\text { ‘+' means detected and '-' means not detected. }\end{array}$
\end{tabular}

\section{Discussion and conclusions}

This experiment compared the effects of different disinfectants on the harmless treatment of dead chickens in the deep burial method. The results showed that the total bacteria content in the liquid in the deep burial pits with three different treatments increased obviously first and then decreased with time. The increase of the total number of bacteria reflects the process of harmless treatment, where the more the total bacteria content increases, the faster the treatment is. The total number of bacteria in quicklime group was the highest, indicating that its treatment effect was the best. E. coli and S. aureus are common pathogenic bacteria in chickens, which need to be killed before the carcass' discharged or utilized. The killing time of harmful bacteria was the fastest in the quicklime treatment group and followed by the calcium hypochlorite group. The slowest was control group. Thus, the harmless treatment effect of quicklime group was the best, of calcium hypochlorite was the second, and of no treatment group was the worst.

Temperature is one of the most important environmental factors affecting the growth and survival of microorganisms, so it is the key factor affecting the efficacy of innocuous treatment of dead chicken. With 
the increase of temperature, the biochemical reaction rate and growth in cells are accelerated, which was reported double for every $10^{\circ} \mathrm{C}$ increase of temperature ${ }^{[5]}$. In this experiment, total bacterial count of quicklime, calcium hypochlorite and the control group reached a highest peak in the temperature in July, and disposal effect reached the best level. E. coli and S. aureus were test at the beginning of summer, while at the end of summer test, they were no longer detected, which may presume a promotion of summer heat on harmful pathogenic microorganisms killing. Therefore, the introduction of quicklime when buried deep can better improve the decomposition ability and harmful bacteria killing ability of dead chicken carcass over a summer, which finally achieve the purpose of harmless treatment of dead chicken in large-scale farms.

\section{Acknowledgments}

We are grateful to all of the people for their help with sample collection. This work was supported by Chinese National Agriculture Research System (CARS-41-G04), Key Technology Support Program of Sichuan Province (2019YFN0009, 2021YFYZ0031).

\section{Reference}

1. J L Xi, H M Dong, Z P Zhu, et al. Research Progress on Composting Treatment of Dead Livestock[J]. Journal of agricultural science and technology, 2010(2):76-80(In Chinese).

2. Y L Xu, L L Wang, G L Gong, et al. Research progress on harmless treatment of animal carcasses infected with epidemic diseases by composting $[\mathrm{J}]$. Animal Husbandry \& Veterinary Medicine, 2015(4):138-141(In Chinese).

3. R F Xue. Public health significance of harmless treatment of dead livestock and poultry[J]. Livestock and poultry industry, 2012, (11):54-57(In Chinese)..

4. X P Wang. Discussion on technology and policy of disposal of dead animals[J]. Gansu Animal and Veterinary Sciences, 2011, 41(6):26-29(In Chinese)..

5. P Huang. The effect of temperature on bacterium growing $[\mathrm{J}]$. The science and technology of gelatin, 2011, 31(1):29(In Chinese). 